\title{
Uma utopia nacional em produção comercial: o caso do programa radiofônico História da Literatura Brasileira (1952-1954)
}

A national utopia in commercial production: the case of Historia da Literatura Brasileira radio program (1952-1954)

Una utopía nacional en producción comercial: el caso del programa de radio Historia da Literatura Brasileira (1952-1954)

DOI: https://doi.org/10.1590/1809-58442021303

\author{
Matan Ankava ${ }^{1}$ \\ https://orcid.org/0000-0002-6351-8574
}

${ }_{1}^{1}$ (Universidade de São Paulo, Faculdade de Filosofia, Letras e Ciências Humanas, Programa de Pós-Graduação em História Social. São Paulo - SP, Brasil).

\section{Resumo}

O presente artigo se propõe a estudar o programa radiofônico "História da Literatura Brasileira" (HLB), produzido por Osvaldo Moles, e transmitido entre os anos de 1952-1954. Parte da chamada era do rádio, o programa parece englobar com êxito os dois modelos que marcaram a história da radiodifusão: a proposta civilizatória-educativa, através da discussão de um cânone literário nacional, e a direção comercial-mercadológica, expressa no sucesso de audiência e crítica que foi o programa. Desta forma, uma realização como $H L B$ evidencia a complexidade do universo radiofônico e sua constituição como ambiente de produção cultural multiforme e polissémico. Neste trabalho, buscamos refletir sobre os sentidos e significados contidos na massificação das temáticas presentes no Programa, que incidiam sobre aspectos como a identidade nacional, a cultura brasileira e os jogos de interesses e disputas por trás da (re)produção destes debates.

Palavras-chave: História do Rádio. História da Literatura Brasileira. Radiocomunicação. Cultura de Massa. Osvaldo Moles.

\begin{abstract}
The following article seeks to study the radio program "História da Literatura Brasileira" ("History of Brazilian Literature" - HLB), produced by Osvaldo Moles, and broadcasted between the years 1952-1954. Part of the so-called "golden age" of the radio in Brazil, the program appears to successfully encompass the two models that have marked the history of broadcasting: the civilizatory-educative proposal, through the discussion of a national literary canon, and the commercial orientation, expressed in the audience and critical success achieved by the program.
\end{abstract}


Therefore, an accomplishment such as HLB evidence the complexity of the radio universe, and its constitution as an environment of multiform and polysemic production. In this paper, we seek to reflect upon the significances contained in the massification of the Program's themes, broaching aspects such as the national identity and Brazilian culture, and the interests and disputes behind the (re)production of these debates.

Keywords: History of Radio. História da Literatura Brasileira. Radio-Communication. MassCulture. Osvaldo Moles.

\section{Resumen}

Este artículo busca estudiar el programa de radio "História da Literatura Brasileira" (Historia de la Literatura Brasileña - HLB), producido por Osvaldo Moles y transmitido entre los años 1952-1954. Parte de la llamada “Era de la Radio”, el programa parece abarcar con éxito los dos modelos que han marcado la historia de la radiodifusión: la propuesta civilizadora-educativa, a través de la discusión de un canon literario nacional, y la dirección de marketing comercial, expresada en la audiencia y el éxito crítico que fue el programa. De esta manera, un logro como HLB resalta la complejidad del universo radio y su constitución como un entorno de producción cultural multiforme y polisémica. En este trabajo, buscamos reflexionar sobre los sentidos y significados contenidos en la masificación de los temas presentes en el Programa, que se centró en aspectos como la identidad nacional, la cultura brasileña y los juegos de intereses y disputas detrás de la (re) producción de estos debates.

Palabras clave: Historia de la radio. Historia de la literatura brasileña. Comunicación por Radio. Cultura de Masas. Moles de Osvaldo.

\section{Introdução: o rádio como objeto da história social}

O Rádio está no táxi, falando de futebol. No boteco em que se toma o café, lá está o Rádio contando quanto pagou o Gualicho. Se vou para casa com o objetivo de encontrar “o bíblico e sereno sossego”, lá está o rádio ligado num musical. Lá dentro, a moçada está ouvindo novela. Então, a gente se fecha no quarto e o rádio do vizinho, em voz bem alta, no programa de calouros, apresenta um “imitador” de Vicente Celestino. Aí, a gente sai de casa, pensando que este mundo está cercado de rádio por todos os lados. Vou para a Rádio Bandeirantes, onde há sempre máquina de escrever de boca aberta... e aí de novo estou no Rádio. É o único lugar em que a gente se liberta. Como, pois, não gostar de rádio se ele está em toda parte? ${ }^{1}$

Assim descreveu Osvaldo Moles, produtor nacional de sucesso, o lugar ocupado pelo rádio na sociedade brasileira de meados do século XX. Essa “onipresença” correspondia à força do rádio como o principal meio de comunicação do país e a um espaço destacado de

1 Revista do Rádio, 1952/Edição 00172 
produção cultural, que levaram a denominação dos anos 1940-1950 como a "Era do Rádio" no Brasil (SEVCENKO, 1998).

De fato, em um país de dimensões continentais, historicamente descentralizado e marcado por baixo letramento e pela desvalorização da leitura² ${ }^{2}$ o rádio apresentava-se como uma verdadeira revolução; poucos anos após a instauração da radiodifusão, suas irradiações ofereciam possibilidades inéditas de atingir múltiplos ouvintes, atravessando os grupos socioeconômicos.

Estudado inicialmente como instrumento através do qual as elites reforçavam sua hegemonia, os estudos mais recentes têm reconhecido a complexidade da indústria

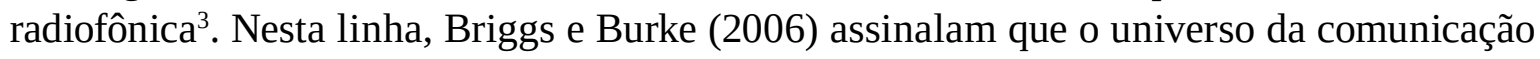
deve ser concebido a partir da participação, de igual peso e importância, de "quem?” (produtores), “para quem?” (audiência) e “o quê?” (conteúdo). Mais adiante, chegaremos a questionar a hermeticidade das funções preenchidas por cada categoria, mas o principal no momento é conceber o rádio como sistema multifacetado, cuja produção está calcada na conjuntura histórica e social onde se realizada.

Portanto, entendemos que só é possível destrinchar alguns dos sentidos do rádio ao reconhecer que:

a sociedade, as pessoas que a formam, constituem uma estrutura que nos permite assumir que os elementos históricos, construídos ou destruídos, não eram apenas elementos de indivíduos isolados, mas imersos em um amplo contexto envolvendo múltiplos fatores que possibilitaram que as coisas acontecessem de uma certa maneira (PANIAGUA, 2008, p. 2).

Essa compreensão, e os procedimentos dela decorrentes, são característicos da chamada "história social” - orientação teórica-conceitual que marca esta pesquisa. Desta forma, a investigação da produção radiofônica integra à análise literária-discursiva também a operação historiográfica, refletindo sobre sua relação com um espaço-tempo determinado, e as continuidades e rupturas que estabelece com as tradições locais.

Assim, acreditamos que a análise de um programa específico demanda seu estudo como produto-resultado, ou melhor, uma expressão de um contexto:

\footnotetext{
2 Utilizamos aqui o termo letramento, e não apenas "analfabetismo”, por destacar que qualquer traço sociocultural não decorre apenas do domínio técnico da leitura, mas sim do lugar que ocupa como hábito. Portanto, em um país de fraca tradição de leitura (SEVCENKO, 2003), a mera alfabetização, promovida nos anos 1920, não gerou uma ampliação real da leitura e a integração de grupos historicamente analfabetos.

3 Como em alguns dos estudos pioneiros no país sobre o rádio: "meio de comunicação com grande poder de penetração entre as massas, muito cedo o rádio e a política se uniram, com objetivos de doutrinação ideológica. E o rádio conseguiu servir aos interesses políticos com 'maquiavélica' eficiência”, segundo Ortriwano (1985, p. 60); ou na leitura que faz Goldfeder da Rádio Nacional: "esta emissora deveria atuar como um mecanismo de CONTROLE SOCIAL, destinado a manter as expectativas sociais dentro dos limites compatíveis com o sistema como um todo. Este controle se exerceria, no entanto, de forma implícita, parcial e difusa, ao contrário dos mecanismos propriamente políticos, através de uma forma determinada de distribuição de bens e valores de participação e obediência (GOLDFEDER, 1980, p. 40 - Grifo no original).
} 
ao descobrirmos a natureza de uma prática particular, bem como a natureza da relação entre um projeto individual e um modo coletivo, descobrimos que estamos analisando, como duas formas de um mesmo processo, tanto a sua composição ativa quanto as condições dessa composição, e em ambas as direções essa é uma relação ativa, complexa e em transformação (WILLIAMS, 2011, p. 67).

\section{Pré-História da Literatura Brasileira: Osvaldo Moles, do jornal ao rádio}

A concepção do rádio como campo social não invalida a importância autoral. Ao contrário, o conhecimento de sua trajetória é fundamental para compreender algumas das experiências e ideais por trás da obra (BOURDIEU, 2007). No caso do programa História da Literatura Brasileira (HLB), isso significa investigar a figura de Osvaldo Moles, produtor do programa $^{4}$. Trata-se de uma tarefa marcada por algumas incertezas, mas que suscita pontos importantes para nossa reflexão.

Nascido em 1913, a família de Moles pertencia às camadas médias-baixas da capital paulista. Não obstante, ao ingressar na “Escola de Commercio D. Pedro II”, Moles já vinha firmando laços com a elite intelectual da cidade (ANKAVA, 2020). Estas sociabilidades se intensificaram quando Moles ingressou em jornais como o Diário Nacional, porta voz do Partido Democrático, e posteriormente do Correio Paulistano, da oligarquia do PRP. Evitando grande aprofundamento, o central aqui é apresentar a proximidade de Moles daquele “caldeirão" intelectual dos anos 1920 e 1930, marcado, sobretudo em São Paulo, pela atuação dos Modernistas.

Bem-sucedido no jornalismo, em 1937, Moles aceita o convite de Assis Chateubriand para colaborar na fundação da Rádio Tupi de São Paulo. Assim, adere ao novo meio de comunicação, já em franco crescimento, com forte dimensão comercial e em crescente disseminação pelas classes populares. Moles permaneceu na "Cacique do Ar” por quatro anos, período do qual restaram pouquíssimos registros.

Em 1941, Moles ingressa na Rádio Record, uma emissora de importância nacional e precursora do rádio comercial: aquelas estações mantidas pela venda de publicidade, de linguagem e conteúdos populares - aqui, no sentido de não eruditos - e com projeção de massificar sua audiência ${ }^{5}$. Essas características, hoje quase que "naturais”, não o eram na época; ao contrário, em seus primeiros momentos, o rádio era visto como instrumento de “elevação cultural”, tendo como emblema o projeto da Rádio Sociedade do Rio de Janeiro.

Com a ascensão do paradigma comercial, marcado pela regulamentação da publicidade radiofônica através do Decreto-Lei $\mathrm{n}^{\circ}$. 21.111, estabeleceu-se um suposto binômio: a lógica "lucrativa”, (re)produzindo fórmulas estabelecidas e bem-sucedidas como programas musicais, concursos, programas de auditório e humor; e a visão “civilizatória”,

4 À época, a função de "produção" frequentemente acoplava também a redação e direção dos programas - caso de Moles e $H L B$.

5 Emissora bastante estudada, sobre os projetos da Record pode-se consultar Mendes (1988) Tota (1990), entre outros. 
buscando a difusão de valores moralizantes e conteúdos eruditos entre as classes subalternas. Essa dicotomia é importante, pois além de sintetizar lógicas operativas, marcou também as reflexões posteriores a respeito do rádio ${ }^{6}$.

A obra de Moles, no entanto, parece colocar em xeque esta polarização. Desde seus primeiros momentos na Record, sua produção incluía conteúdos ligados à literatura e à história. De acordo com a imprensa, entre suas qualidades, estava justamente a capacidade de conciliar temas vistos como educativos e ampla audiência ${ }^{7}$. As reportagens do período evidenciam o sucesso que obteve o radialista, apelidado de "a bomba atômica da Record". Sua grande reputação também foi evidenciada pelas repetidas conquistas do Prêmio Roquette Pinto, instaurado em 1950.

\section{História da Literatura Brasileira, da gaveta às ondas radiofônicas}

Apesar do êxito, em fins de 1950 anuncia-se a saída de Moles da Record. Em uma entrevista posterior, o radialista associou o movimento a insatisfação profissional, pois vivenciava na Record “a morte das ideias que nunca foram aquilatadas nem avaliadas naquilo que elas poderiam ter de eminentemente radiofônicas ${ }^{9}$ ”. Moles passa então à Rádio Bandeirantes. Fundada em 1937, a emissora se propôs inicialmente a "estabelecer novos rumos no rádio paulista, iniciando com programas religiosos, programas culturais e educativos”10. Inserindo-se em um mercado que já vinha sendo marcado pela lógica massificada, o projeto original se mostrou insustentável e a Bandeirantes foi "popularizando" sua programação.

Após um período como parte do conglomerado das Emissoras Unidas - do qual fazia parte também a Record - a estação foi adquirida por Adhemar de Barros, principal político paulista da época, que a repassou a seu genro, João Jorge Saad. Foi sob o controle de Saad que a Bandeirantes atingiu seu auge: em 1950 foi a primeira emissora brasileira a transmitir ininterruptamente, 24 horas por dia e, no decorrer da década, algumas de suas irradiações foram líderes nacionais de audiência.

Foi aqui que Moles conseguiu articular as condições necessárias para a produção de seu programa História da Literatura Brasileira, cujos roteiros datilografados compõem o nosso

\footnotetext{
6 Por exemplo, em Calabre (2003, p. 162): “o primeiro [modelo radiofônico] era centrado na estreita ligação entre o rádio, a educação nacional e o controle estatal (este é o caso da maioria dos países europeus na primeira metade do século XX). O segundo, estritamente comercial e para o qual o sistema norte-americano serve de paradigma, era formado por um conjunto de emissoras montadas sobre uma estrutura predominantemente comercial, voltadas para os interesses do mercado e financiadas pela verba da venda de publicidade". 7 Por exemplo, nos casos de Os grandes processos da história, "essa audição [que] engrandece o rádio por sua essência, pela sua atração, pelo seu conteúdo, pelo seu valor” (Correio Paulistano, 1946. Edição 2768); ou O crime não compensa, "magnífico programa, não só pelo interesse que desperta, graças à maneira por que é conduzido, mas - e principalmente, pelo que encerra de útil e educativo" (Revista do Rádio, 1949. Edição 00014). Ver também Ankava (2020).

8 Correio Paulistano, 1946. Edição 27611, ou “uma das principais e das mais queridas figuras do sem-fio paulistano” (Revista do Rádio, 1949. Edição 00014).

9 Entrevista Moles ao jornal Radar, 1951. Arquivo pessoal Osvaldo Moles. Micheletti (2015) associa a saída diretamente a recusa da emissora de produzir o $H L B$ - colocação que não conseguimos confirmar e/ou refutar.

10 Correio Paulistano, 1954\Edição 29999.
} 
corpus $^{11}$. Diante da precaridade de registros gravados, quadro generalizado do rádio paulista, os roteiros são fontes preciosas para conhecermos o universo da produção radiofônica; aqui, encontramos 24 programas (Quadro 1) - conjunto que corresponde, provavelmente, a 1/6 dos episódios transmitidos durante os dois anos e meio de existência do programa.

Quadro 1 - Listagem dos episódios consultados

\begin{tabular}{|l|l|}
\hline $\begin{array}{l}\text { Data de } \\
\text { transmissão }\end{array}$ & Tema \\
\hline $07 / 04 / 1952$ & “elementos de formação da nossa língua” \\
\hline $14 / 04 / 1952$ & “primeiros poetas, escritores e historiadores do Brasil” \\
\hline $21 / 04 / 1952$ & Sobre Gregório de Matos (continuação na semana seguinte) \\
\hline $31 / 05 / 1952$ & “Apresentação da História da Literatura Brasileira” \\
\hline $02 / 06 / 1952$ & “final do capítulo sobre os épicos da história mineira” (próximo episódio sobre \\
\hline $16 / 06 / 1952$ & $\begin{array}{l}\text { "Vida e a obra de Tomaz Antonio Gonzaga - O Dirceu da arcadia mineira” } \\
\text { (continuação na semana seguinte) }\end{array}$ \\
\hline $23 / 06 / 1952$ & “A segunda fase da vida e da obra de Tomaz Antonio Gonzaga - O Dirceu da \\
\hline $30 / 06 / 1952$ & “José Inácio de Alvarenga Peixoto” (próx. ep. “os últimos árcades” \\
\hline $14 / 07 / 1952$ & “A luta pela liberdade de pensamento” (próx. ep. “os oradores”) \\
\hline $28 / 07 / 1952$ & “José Bonifácio de Andrada e Silva” \\
\hline $18 / 08 / 1952$ & “O Romantismo” \\
\hline $01 / 09 / 1952$ & “Porto Alegre e outros românticos” \\
\hline $08 / 09 / 1952$ & “a arte de morrer com urgência” \\
\hline $15 / 09 / 1952$ & “o indianismo de Gonçalvez Dias” \\
\hline $22 / 09 / 1952$ & “vida e obra de Gonçalves Dias” \\
\hline $29 / 09 / 1952$ & “vida e obra de Gonçalves Dias” (incompleto) \\
\hline $06 / 10 / 1952$ & “Gonçalves Dias e a poesia brasileira” \\
\hline $03 / 11 / 1952$ & “Noite na Taverna, de Álvares de Azevedo” \\
\hline $10 / 11 / 1952$ & “os últimos dias de Álvares de Azevedo” (próx. ep. Fagundes Varela) \\
\hline $17 / 11 / 1952$ & “Fagundes Varela” (próx. ep. Fagundes Varela) \\
\hline $24 / 11 / 1952$ & “Fagundes Varela” (próx. ep. “O cântico do calvario”) \\
\hline $09 / 02 / 1953$ & “Castro Alves” (próx. ep. “Navio Negreiro, de Castro Alves”) \\
\hline
\end{tabular}

11 O material se encontra no acervo pessoal de Moles, mantido pela sua família. 


\begin{tabular}{|l|l|}
\hline $\begin{array}{l}\text { Data de } \\
\text { transmissão }\end{array}$ & Tema \\
\hline 02/03/1953 & $\begin{array}{l}\text { "Navio Negreiro, de Castro Alves”, reprise (próx. ep. “A obra social de Castro } \\
\text { Alves”) }\end{array}$ \\
\hline $15 / 03 / 1954$ & Poema “Fugindo ao cativeiro”, de Vicente de Carvalho \\
\hline
\end{tabular}

Fonte: acervo da pesquisa. programa:

O episódio intitulado "apresentação" sinaliza algumas das particularidades do

História da Literatura Brasileira - tarefa que o rádio empreende sem oferecer nem divertimento, nem prêmios, nem shows, nem "suspenses”, nem "clímax" aos seus ouvintes. Apenas uma História da Literatura para o povo, sem espírito de crítica e, provavelmente, sem espírito até (HLB, ep. 31/05/1952, p. 2-3).

Através da negação, o trecho indica algumas das tendências radiofônicas do momento e as diferencia da proposta de $H L B$. Moles ainda reforça essa distinção em uma entrevista no jornal:

sabe-se - responde Moles - que a preferência do ouvinte recai nos $<<$ shows $>>$ exclusivamente diversivos. Sabe-se também que um $<<$ oba $>>$ de cantora de auditório é mais apaixonante do que uma transmissão sobre Gregório de Matos [...] a criação do auditório, com todas as suas mazelas e <<obas $>>$, foi que atrasou extraordinariamente a marcha para o rádio adulto, embora ao alcance de todos. $<<$ História da Literatura Brasileira $>>$ é um programa popular. Os próprios intelectuais que colaboram conosco o dizem [...] o programa expõe em linguagem corrente, ao alcance de quase todos os ouvintes ${ }^{12}$.

Ou seja, independentemente de sua temática e abordagem menos popularescas, o programa busca não ser menos popular ou menos acessível. Este direcionamento ia ao encontro da projeção massificada do rádio comercial, presente à época em 95\% dos domicílios metropolitanos (McCANN, 2004). Junto a isso, foi sustentado também pelas perspectivas políticas dos seus participantes:

Hoje a literatura não é mais artigo de luxo. Sai do povo para o povo. Portanto, o seu grande instrumento deve ser o rádio. Estou convencido de que este programa organizado por Osvaldo Moles e Mario da Silva Brito vai despertar não só interesse, mas, acordar vocações nas casas que o vão escutar” (HLB, ep. 31/05/1952, p. 4).

12 Recorte de jornal não identificado, arquivo pessoal de Osvaldo Moles. 
Aqui, Oswald de Andrade, um dos supervisores do programa, defende a importância de o povo ocupar-se com a literatura. Para tal, essa arte deve romper com suas barreiras históricas e "deve ser" propagada por um meio de comunicação genuinamente massivo, o rádio.

Em outra passagem, Oswald de Andrade exalta os esforços de Moles e Brito, que elogia por "difundir na massa do grande público os valores supremos da inteligência brasileira” (HLB, 1952). Esta perspectiva resgata sinteticamente um dos principais objetivos do movimento modernista: a disseminação de um imaginário nacional e a construção de uma brasilidade compartilhada pela população. Missão que consideramos resumida na denominação dos modernistas como "missionários de uma utopia nacional-popular” (BARBATO, 2004, p. 136).

As afinidades de $H L B$ com o modernismo se tornam ainda mais evidentes se considerarmos o corpo de colaboradores do Programa: além de Oswald, participavam da equipe de “supervisão” Jamil Almansur Haddad e Sérgio Milliet; o programa contava ainda com a "Colaboração e orientação" de Mário da Silva Brito e Moles assumia as tarefas de “Redação, pesquisa e direção geral”.

Conforme podemos notar na relação dos episódios, Moles e seus colaboradores adotavam uma apresentação cronológica: ao episódio "elementos de formação da nossa língua” segue, na semana seguinte, o “primeiros poetas, escritores e historiadores do Brasil”; na sequência da arcádia mineira, apresentada por meio de figuras como Cláudio Manuel da Costa e Tomás Antonio Gonzaga, vêm os episódios relativos ao surgimento do Romantismo - inicialmente, na Europa, e, em seguida, no Brasil.

Consideramos que a escolha da continuidade cronológica resultava em dois efeitos centrais: primeiro, estabelece uma narrativa com linearidade temporal, que reforça uma metodologia clara e de credibilidade científica; segundo, gera um encadeamento de apresentações, que não apenas facilita o acompanhamento, como atua no sentido de cativar o ouvinte.

Esse último aspecto representa um fator fundamental para a produção comercial. É interessante notar que a audiência não se limitava a aguardar, passivamente, o desenvolvimento da programação, mas exercia também aquilo que podemos chamar de agência sobre a produção radiofônica (ANKAVA, 2020). Mesmo que em HLB não encontramos uma participação autoral do público, seus roteiros expõem outra forma de engajamento:

Não esperávamos que “Navio Negreiro” ([seja]...) de fato, o poema que até agora, nestas audições da História da Literatura Brasileira, encontrou melhor acolhida, maior repercussão, por assim dizer. Muitos, não o ouviram. E foram justamente os que não ouviram este programa, que andam pedindo repetição (...) aqueles que nos estimularam com suas cartas, telegramas, telefonemas e aos cronistas de rádio que nos animaram, aqui fica não o nosso agradecimento, mas a nossa alegria por ver a acolhida proporcionada ao maior poema brasileiro (HLB, ep. 02/03/1952, p. 3). 
O informe deixa evidente uma dimensão ativa dos ouvintes, que ultrapassava o exercício, ou não, da escuta. Estes contavam com diferentes formas e instrumentos para transmitir seus desejos, sendo que a variedade de canais através dos quais foi solicitada a reprise de "Navio Negreiro" indica a intensidade e importância deste tipo de pedidos/ demandas. Ressaltamos que, evidentemente, não pretendemos equiparar a força criativa dos produtores e do público; ao invés, buscamos indiciar a complexidade dos processos de produção cultural e a insuficiência de sua concepção verticalizada.

Todos os episódios de História da Literatura Brasileira iniciavam com um anúncio do seu patrocinador, Caixa Econômica do Estado de São Paulo. Tratava-se de uma estrutura comum no rádio, que sugere a centralidade da publicidade. No nosso caso, é a natureza pública do anunciante que desperta curiosidade: fundado em 1917 sob a iniciativa do presidente do estado Altino Arantes ${ }^{13}$, o banco contava com autonomia administrativa, mas submetido às diretrizes da Secretaria da Fazenda. Suas agências multiplicaram-se pelo estado paulista ao longo das décadas seguintes, chegando a configurar, no início dos anos 1950, uma autarquia - entidade pública de administração indireta ${ }^{14}$.

Vale recordarmos aqui que $H L B$ parece distanciar-se das temáticas recorrentes à época, o que talvez explique porque "seu plano dormia desde muito em gavetas de chefes de propaganda de agências e de emissoras e de departamentos publicitários de firmas comerciais ${ }^{15}$ ". Encontra-se aqui uma evidência definitiva, vindo do nosso protagonista, da importância que os patrocinadores detinham sobre a programação cultural.

Assim, a produção de $H L B$ representa uma parceria entre a administração pública e uma emissora privada: a primeira aproveitava a popularidade da radiodifusão; enquanto a segunda fazia uso de capital público para - literalmente "no fim das contas" - obter lucro próprio. Segundo nossas pesquisas, o mecenato estatal não era prática recorrente, mas ocorreu em, ao menos, mais duas produções de Moles - curiosamente, todas irradiadas pela "adhemarista" Bandeirantes.

Nos roteiros analisados de História da Literatura Brasileira, os anúncios da Caixa Econômica apresentavam dois eventos centrais: 1) a inauguração de uma agência bancária que operava 24 horas por dia, localizada na Praça Ramos de Azevedo, região central da cidade; e 2) orientações vinculadas aos projetos de poupança do Banco. Em ambos os casos, os anúncios se endereçavam ao ouvinte de uma forma direta, colocando o banco que nós entendemos como figura metonímica do próprio Estado - a serviço do indivíduo ("aberto noite e dia, para melhor atender a sua economia" [18/08/1952 - Grifo nosso]) ou da população toda, como uma coletividade ("separe dez por cento de tudo que você ganha, e deposite-os no plano popular para enriquecer o povo, da Caixa Econômica Estadual” [ep. 03/11/1952, p. 1]).

13 Cargo corresponde, atualmente, ao posto do governador.

14 Disponível em: http://www.saopaulo.sp.gov.br/ultimas-noticias/nossa-caixa-ha-90-anos-o-banco-dos-brasileiros-de-sao-paulo/. Acesso em: 8 fev. 2020.

15 Revista do Rádio, 1951. Edição 00089. 
Mesmo que os anúncios estejam direcionados para a totalidade da população - o coletivo do "povo", ou em "cada cidadão" - esse chamado popular deve ser visto em sua complexidade: por um lado, recomenda uma porcentagem de economia que, de certo, não era viável a todos; por outro, ocorre após um aumento significativo do salário mínimo, em 1952. Consequentemente, suscita algumas ponderações: ou, apesar das pretensões de seus criadores, $H L B$ não se tornou um programa realmente massificado; ou, caso tenha sido, a campanha pode ser vista como uma espécie daquilo que chamaríamos hoje de "educação financeira”, evidenciando a ampliação das camadas médias urbanas.

Por fim, concentremo-nos em alguns dos tópicos mais presentes nos roteiros. É importante salientar que, não obstante sua plataforma massificada, História da Literatura Brasileira não deixou de apresentar conteúdos bastante eruditos: no episódio sobre "os épicos da história mineira”, relacionam-se os estilos narrativos de Caramuru com a literatura ocidental clássica: “como na Ilíada, de Homero, a atenção do espectador se desvia do cenário geral da batalha, para concentrar-se em uma cena sugestiva da batalha (ep. 02/06/1952, p. 4); ou quando o personagem de Victor Hugo oferece uma síntese do romantismo, segundo o qual "o que nossa escola chamada romantismo procura é a realidade da beleza, misturando o sublime e o grotesco, o céu e o inferno, o sorriso e a lágrima” (ep. 18/08/1952, p. 5).

As duas passagens exemplificam a atenção dada por Moles e a equipe de $H L B$ para a qualidade intelectual do programa, expressa também no uso frequente de passagens literárias vinculadas às temáticas, figuras e obras discutidas. Assim, os roteiros reproduzem trechos extensos de Marília de Dirceu, Juca Pirama, Navio Negreiro, entre outros. Neste sentido, se justificam também as frequentes menções a pesquisas e estudiosos da área de literatura, como Ronald de Carvalho, José de Alencar, José Veríssimo e Sílvio Romero. Consideramos que essas referências visavam inserir o programa em uma tradição de estudos sobre a formação da literatura nacional, aproximando a produção radiofônica de obras canônicas.

É interessante perceber que são diversos temas - sociais, culturais, políticos - que permeavam História da Literatura Brasileira. Inclusive, em diferentes episódios vê-se que os temas e figuras em destaque não são voltados para a literatura, mas sim para eventos históricos que marcaram a formação do país. Nesta linha, episódios sobre o arcadismo mineiro ou sobre Castro Alves e Vicente de Carvalho, enfatizam o contexto social de sua composição, como a Inconfidência Mineira ou a abolição da escravatura, respectivamente, em detrimento dos aspectos formais ou o conteúdo artístico, presentes em menor grau.

Os exemplos são numerosos, e auxiliam na compreensão deste apontamento:

levas crescentes de escravos da Guiné concorriam para o desenvolvimento das herdades (sic). Escravos trabalhavam agora nos engenhos e nas granjas. $\mathrm{O}$ braço branco agora foi sendo substituído pelo braço negro, nos trabalhos rudes. Portugueses viviam no ócio sem cuidados com as tarefas mais duras. Olinda florescia (...) o grande comércio do Brasil, naquele tempo, era este: Exportamos pau brasil. Importamos cativos! (HLB, ep. 14/04/1952, p. 3). 
Extraído do episódio “primeiros poetas, escritores e historiadores do Brasil”, vêse nitidamente a preocupação de Moles de expor também elementos relativos ao contexto socioeconômico e à conjuntura histórica. Assim ocorre também em um dos capítulos sobre o Arcadismo:

Vida e a obra de Tomaz Antonio Gonzaga - O Dirceu da arcadia mineira”, cujo início relata o momento histórica da Inconfidência Mineira: "nos últimos vinte anos do século dezoito, o Brasil está francamente em guerra surda contra os que o mantém acorrentados como colônia. Por ordem se sua Majestade (que Deus guarde) serão desgredados todos aquele que esconderem o fruto de suas rendas, nas minerações (...) São Paulo, Bahia, Minas - do sul à norte a reação predominava. O governo português empregava a força (...) foi nesse ambiente que viveu, lá em Vila Rica, Minas Gerais, Tomas Antonio Gonzaga (HLB, ep. 16 jun. 1952, p. 2-3).

Mais uma vez, nota-se o entrelaçamento entre literatura e sociedade, no qual frequentemente a narrativa histórica supera a reflexão estilístico-literária.

No nosso entender, mais que originar do nexo entre a literatura e a história, este movimento visava reforçar a construção de uma identidade nacional, através da reconstituição de um passado. Neste sentido, História da Literatura Brasileira seguia a linha do "rádio educador", mas deslocou os holofotes da instrução técnica para a formação de uma brasilidade compartilhada e de sentimentos ufanistas. Ao longo dos roteiros, foi possível encontrar diferentes menções a tópicos como a colonização, miscigenação, independência e outros aspectos que, naturalmente, tiveram repercussão literária, mas parecem atuar mais no sentido de estabelecer tradições e passado coletivo. Por fim, é necessário ainda se atentar para a recepção do programa. Ao que parece, o último episódio de $H L B$ foi transmitido em 10/01/1955 ${ }^{16}$, sendo que os jornais anunciaram esta possibilidade desde os fins de $1954^{17}$. A própria duração do programa já evidencia que o resultado satisfazia todos os envolvidos - produtores, público e patrocinador. O fato da Bandeirantes renovar o contrato de Moles - em fevereiro de 1954, quando HLB comemorava já dois anos -, também reforça essa hipótese.

Os jornais da época também testemunham o êxito do programa: “"História da Literatura Brasileira', assinala um marco divisório no rádio nacional. Essa audição é - sem favor - o início da moralização cultural dos programas radiofônicos"18; "sensação da rádio paulista [...] esta audição define até onde o rádio pode chegar, quando voltado para sua alta finalidade educativa e cultural ${ }^{19}$ ". Não deixaram também de celebrar seu sucesso comercial:

16 Revista do Rádio, 1955. Edição 00278.

17 Radiolândia, 1954. Edição 00034.

18 Revista Sombra, 1952. Edição 00124.

19 Revista do Rádio, 1952. Edição 00156. 
“notável programa de Osvaldo Moles, 'História da Literatura Brasileira', que tanto sucesso vem obtendo desde o seu início ${ }^{20 ”}$, e “Esse programa é o primeiro em audiência, às 21hs das segundas feiras, o que vem provar que o público ouvinte também gosta de audições de elevado nível cultural ${ }^{21}$.

Nota-se que, além de exaltar o sucesso “comercial”, os periódicos enfatizavam também as contribuições educativas e morais de História da Literatura Brasileira. Essa avaliação vai então ao encontro dos nossos apontamentos anteriores: inicialmente, as denúncias - mais, ou menos - veladas contra a baixa qualidade da programação radiofônica; e, em segundo lugar, a existência de um projeto político-cultural por trás de um produto - e meio de comunicação - marcadamente comercial. São esses os dois aspectos que julgamos de maior interesse e contribuição na hora de avaliar os significados por trás do programa.

\section{Considerações finais}

Diferentes estudos têm abordado a oposição entre dois modelos radiofônicos: o “educador”, promovido por emissoras como a Rádio Sociedade do Rio de Janeiro e a Rádio Educadora Paulista, e voltado para aquilo que seus protagonistas, costumeiramente membros da elite intelectual, consideravam como cultura; o outro “comercial”, orientado por interesses financeiros e dirigido por forças do mercado ${ }^{22}$.

Frequentemente, considera-se que o primeiro modelo predominava entre os pioneiros do rádio, mas foi substituído pelo segundo com o crescimento da publicidade radiofônica. Uma das consequências deste quadro foi a deslegitimação do rádio como ambiente criativo: seja pela desclassificação do seu público e formatos - crítica sintetizada em expressões como “macacas de auditório" -; ou por considerá-lo um meio de baixo valor cultural (ADORNO; HORKHEIMER, 1985). No nosso entender, um caso como História da Literatura Brasileira revela a importância de matizar esta concepção, evidenciando as múltiplas facetas da Era do Rádio.

Transcendendo a discussão literária, o programa representa um projeto de ensino histórico e cultural, que desemboca em uma formação identitária-nacional. De fato, os criadores - paulistas - do programa radiofônico deram continuidade ao projeto - paulista dos modernistas, que tinha como discurso central a democratização da cultura:

daí a ideia de que era preciso arrancar a cultura dos 'grupos privilegiados', atribuindo-lhe uma dimensão a partir da qual todos pudessem desfrutar. Tratava-se, antes de tudo, contemplar a população marginalizada do cenário

20 Correio Paulistano, 1954. Edição 30259.

21 Revista do Rádio, 1953ไEdição 00201

22 Por exemplo em Calabre (2003, p.162): “o primeiro [modelo] era centrado na estreita ligação entre o rádio, a educação nacional e o controle estatal (este é o caso da maioria dos países europeus na primeira metade do século XX). O segundo, estritamente comercial e para o qual o sistema norte-americano serve de paradigma, era formado por um conjunto de emissoras montadas sobre uma estrutura predominantemente comercial, voltadas para os interesses do mercado e financiadas pela verba da venda de publicidade". 
da cultura (...) o que nos permite designá-los como missionários de uma utopia nacional-popular” (BARBATO, 2004, p. 136 - Grifos no original).

O mais interessante, porém, no nosso entender, é refletir sobre os significados da massificação daquela cultura, selecionada pelos criadores de $H L B$. Isso porque, o projeto de universalização de um cânone nacional representa uma "tradição seletiva”:

o que nos termos de uma cultura dominante efetiva, é sempre assumido como 'a tradição', ‘o passado significativo’. Mas sempre o ponto-chave é a seleção - a forma pela qual, a partir de toda uma área possível do passado e do presente, certos significados e práticas são escolhidos e enfatizados, enquanto outros significados e práticas são negligenciados e excluídos (WILLIAMS, 2011, p. 54).

Nesta ótica, $H L B$ corresponde à ampla disseminação de uma gênese sociocultural que pouco dialogava com a heterogeneidade de tradições e expressões artísticas que compunham o Brasil de meados do século XX. Assim, ao mesmo tempo que se propunha a realizar um movimento "civilizatório", representava também a exclusão de outros corpos, como a cultura popular e outras tradições, que não pertenciam aos centros hegemônicos.

As colocações de Dalcastagnè (2007) a respeito das relações entre "representatividade" e literatura ajudam a esclarecer as consequências desse processo:

Aqueles que estão objetivamente excluídos do universo do fazer literário, pelo domínio precário de determinadas formas de expressão, acreditam que seriam também incapazes de produzir literatura. No entanto, eles são incapazes de produzir literatura exatamente porque a definição de "literatura" exclui suas formas de expressão. Ou seja, a definição dominante de literatura circunscreve um espaço privilegiado de expressão, que corresponde aos modos de manifestação de alguns grupos, não de outros (DALCASTAGNÈ, 2007, p. 17).

A “invisibilidade” de sujeitos da arte ainda afeta sua identidade, já que "reconhecerse em uma representação artística, ou reconhecer o outro dentro dela, faz parte de um processo de legitimação de identidades, ainda que elas sejam múltiplas” (DALCASTAGNÈ, 2007, p. 14). No caso da cultura nacional, que incide diretamente sobre a identidade de um povo, a propagação, hierarquizada, de um cânone literário relega a segundo plano aqueles cuja "primeira” literatura - a que consideram como "deles" - não faz parte do corpo contemplado.

Concluímos então com duas ponderações sobre aquilo que julgamos ser os principais significados da massificação cultural, à luz de História da Literatura Brasileira. Primeiro, 
sua constituição como campo em disputa - e sobretudo em conciliações. Se, por um lado, a literatura - metonímia de todo um conjunto cultural - foi amplamente socializada, ela não deixou de ser uma força de partilha, firmando, paralelamente, um comum e seus recortes (RANCIÈRE, 2005). Ou seja, considerando a apologia feita por Oswald de Andrade, a literatura talvez deixou de ser "um artigo de luxo", mas seguiu produzida e definida por uma parcela pequena. Ao mesmo tempo, afirmando o papel da audiência, parece crível defender uma maior participação do "povo", mesmo que por vezes primordialmente como força consumidora.

Segundo, o Programa expõe as dinâmicas e reestruturação dos grupos hegemônicos: no universo da cultural massificada, a intelectualidade necessitava dialogar cada vez mais com os produtores “comerciais”, conhecedores da arte de popularizar. Paralelamente, observase uma transferência de responsabilidades entre o Estado e o setor privado - notadamente os meios de comunicação, cujo poder e disseminação crescem constantemente. Assim, continuava possível uma "utopia nacional-popular", mas independente do poder público, e cuja popularidade traduzir-se-ia em audiência e lucro.

\section{Referências}

ADORNO, T. W.; HORKHEIMER, M. Dialética do esclarecimento: fragmentos filosóficos. Rio de Janeiro: Jorge Zahar Ed., 1985.

ANKAVA, M. Modernização não é Mole(s): rádio e produção cultural em São Paulo, 1937-1962. Dissertação de Mestrado em História, UNIFESP, 2020.

BARBATO JR., R. Missionários de uma utopia nacional-popular: os intelectuais e o Departamento de Cultura de São Paulo. São Paulo: Anneblume/FAPESP, 2004.

BOURDIEU, P. A economia das trocas simbólicas. São Paulo: Perspectiva, 2007.

BRIGGS, A.; BURKE, P. Uma história social da mídia: de Gutenberg à Internet. Rio de Janeiro: Jorge Zahar Ed., 2006.

DALCASTAGNÈ, R. A auto-representação de grupos marginalizados: tensões e estratégias na narrativa contemporânea. Letras de Hoje. Porto Alegre, v. 42, n. 4, p. 18-31, dez. 2007.

GOLDFER, M. Por trás das ondas da Rádio Nacional. Rio de Janeiro: Paz e Terra, 1981.

MICHELETTI, B. D. Osvaldo Moles: O legado do radialista. Dissertação de Mestrado, UNIP, 2015.

MOLES, O. História da Literatura Brasileira. Roteiros de rádio do acervo pessoal de Osvaldo Moles. 1952-1954.

PANIAGUA, J. La história social en la diván del psicoanalista. Revista História Social, n. 60, p. 193200, 2008.

RANCIÈRE, J. A partilha do sensível: estética e política. São Paulo: Editora 34, 2009.

SEVCENKO, N. (org.). História da Vida Privada no Brasil - 3. São Paulo: Companhia das Letras, 1998.

SEVCENKO, N. Literatura como missão, tensões sociais e criação cultural na primeira república. São Paulo, Companhia das Letras, 2003. 
TOTA, A. P. A locomotiva no ar: rádio e modernidade em São Paulo, 1924-1934. São Paulo: Secretaria de Estado da Cultura/PW, 1990.

WILLIAMS, R. Cultura e sociedade: de Coleridge a Orwell. Petrópolis, RJ: Vozes, 2011.

\section{Matan Ankava}

Doutorando em História Social pela Universidade de São Paulo (USP). Mestre em História pela Universidade Federal de São Paulo (UNIFESP). E-mail: matan.ankava@gmail.com.

Recebido em: 16.03.2020

Aprovado em: 21.03.2021 